\title{
LABORATÓRIOS DE ESCUTA
}

\author{
Maria Raquel da Silva Stolf \\ Universidade do Estado de Santa Catarina (UDESC, Brasil)
}

\section{Resumo}

O presente texto aborda investigações em torno de experiências de silêncio, bem como acerca de propostas que envolvem uma escuta porosa, reflexões que dialogam com autores como Roland Barthes, Jean-Luc Nancy, Brandon LaBelle, Peter Galison, entre outros. Tais investigações movem o processo dos trabalhos Assonâncias de silêncios [sala de escuta] (20082010) e 60 silêncios empilhados (2010-2014), duas instalações que articulam relações entre componentes sonoros e escritos, propondo situações de leitura e escuta de silêncios. Apresenta-se também reflexões sobre as intersecções entre silêncio e ruído, a partir da referência de John Cage, do silêncio como interrupção de sentido e acerca de uma espécie de silêncio acústico: as localizações do silêncio - onde e aonde acontecem os silêncios? No encontro ou desencontro entre audição, escuta, contexto e sentido? Porém, como propor um silêncio acústico?

\section{Palavras-chave: INSTALAÇÃO SONORA; SILÊNCIO ACÚSTICO; ESCUTA POROSA; SITUAÇÕES DE LEITURA/ESCRITA/ESCUTA; LABORATÓRIOS DE ESCUTA}

\section{LISTENING LABORATORIES}

\section{Abstract}

This paper seeks to examine researches about silence experiences as well as about proposals involving a porous listening, reflections that dialog with authors like Roland Barthes, Jean-Luc Nancy, Brandon LaBelle, Peter Galison, among others. Such investigations move the process of two installations, Silences assonances [listening room] (2008-2010) and 60 stacked silences (2010-2014), that articulate relations between sound and written components by proposing situations of reading and listening silences. It presents also reflections on the intersections between silence and noise, from the reference to John Cage, and on silence as a sense interruption and about a kind of acoustic silence: the locations of silence - where and to where silences happen? In the meeting or mismatch between hearing, listening, context and sense? However, how to propose an acoustic silence?

\section{Keywords: SOUND INSTALLATION; ACOUSTIC SILENCE; POROUS LISTENING; READING/WRITING/LISTENING SITUATIONS; LISTENING LABORATO- RIES}

\footnotetext{
Stolf, Maria Raquel da Silva. 2015. "Laboratórios de escuta". AusArt 3 (2): 202-214. DOI: 10.1387/ausart.15960
}

\section{AUSART}




\section{ANTECEDENTES}

Adentrarei no presente texto investigações que atravessam o processo de Assonâncias de silêncios [sala de escuta] (2008-2010) e 60 silêncios empiIhados (2010-2014), instalações que articulam relações entre componentes sonoros e escritos, propondo situações de leitura, escrita e escuta de silêncios. Tais trabalhos integram o projeto Assonâncias de silêncios ${ }^{1}$, que envolve a tentativa de propor pausas e silêncios em contextos públicos e privados, por vezes de um modo quase imperceptível, bem como, envolve as ações de registrar e colecionar silêncios, propondo a circulação dessas compilações em publicações impressas e sonoras, entre outras formas de apresentação.

Algo que tem movido o processo de minhas pesquisas recentes ${ }^{2}$ consiste nas reflexões em torno das experiências de audição e escuta, podendo-se ou não envolver concretamente a presença do elemento sonoro. Como aponta Steve Roden (2005), a arte sonora nem sempre toma a forma de som, mas geralmente propõe ao espectador pensar sobre o som, sobre os atos e experiências de ouvir e escutar. As propostas sonoras têm "o potencial de ampliar a percepção de uma pessoa de um espaço (ou talvez até do mundo), através da experiência da escuta - e escutar focado aumenta a experiência" (trad. nossa). O som pode ocupar e modificar lugares, criando outros espaços e catalisando experiências acústicas. Max Neuhaus (2012) enfatiza que seu "foco não é produzir sons que serão exibidos para os ouvidos das pessoas, mas em afetar o modo como elas percebem um espaço através de um ajuste ou alteração de seus sons"3 (trad. nossa).

Deste modo, se os usos heterogêneos do som por artistas sinalizam propostas que instigam relações específicas entre os atos de ouvir e de escutar, pressupõe-se a existência de diferenças entre eles, numa espécie de embate infra-mince entre o que e como se ouve e o que e como se escuta. Sobre esse campo variante de relações, Roland Barthes enfatiza que ouvir implica um "fenômeno fisiológico", enquanto que "escutar é um ato psicológico. Pode-se descrever as condições físicas da audição (seus mecanismos), recorrendo-se à fisiologia da audição; a escuta, porém, só se pode definir por seu objeto, ou, se preferirmos, sua intenção" (Barthes [1982] 1990, 217). Em seguida, ele aborda três tipos de escuta: uma escuta do índice, em que se escuta num estado de alerta (onde a orelha, imóvel, captura os indícios diante de si); uma escuta dos signos, de decifração, em que se escuta segundo certos códigos (escutar implica em ler e decodificar); e uma escuta que não visa signos determinados, nem aquilo que é dito ou emitido, mas "aquele que fala, aquele 
que emite", uma escuta que se desenvolve num espaço intersubjetivo e que é ativa, uma escuta que fala, circula, desagrega e que inclui uma polissemia (ao contrário de uma escuta intencional, de um 'querer ouvir' inteiramente consciente).

Dialogando com Barthes, Jean-Luc Nancy $(2007,33)$ sublinha que escutar "é estar ao mesmo tempo, afora e adentro, estar aberto desde fora e desde dentro, e consequentemente, de um a outro e de um em outro" (trad. nossa). A escuta ocorre ao mesmo tempo que o "acontecimento sonoro" ouvido/escutado e implica sempre a existência de uma duração (pois o som não é instantâneo, mas soa e ressoa, chega e parte). Nancy $(2007,20)$ enfatiza ainda que escutar implica em "aguçar" o ouvido, sendo que "Estar à escuta é sempre estar nas margens do sentido ou em um sentido de borda e extremidade, é como se o som não fosse justamente outra coisa que essa borda, essa franja ou essa margem" (trad. nossa). Portanto, seria possível manter a escuta oscilando na margem, nessa borda de sentido? Como propor essa oscilação? Como ela pode permanecer próxima a uma iminência de sentido, mas num estado movediço?

\section{ASSONÂNCIAS DE SILÊNCIOS}

O trabalho Assonâncias de silêncios [sala de escuta] (Fig. 1) partiu de um interesse por situações de escuta e sondagem de silêncios, a partir do processo de colecionar silêncios em gravações de áudio e na construção de notasdesenhos, em exercícios de intersecção entre registros sonoros e anotações/ notações ${ }^{4}$. O trabalho teve início com a proposta de construção de um sistema de isolamento acústico de uma área dentro de um espaço expositivo, que foi concretizada através da construção de uma cabine de aço carbono (utilizada originalmente para audiometria de campo), com isolamento de quarenta decibéis. A sala possui em seu interior um fone "abafador de ruídos" (com isolamento de vinte e quatro decibéis), uma lâmpada e uma banqueta com altura regulável, além de dois visores acústicos e uma prateleira na parte externa, sobre a qual estão depositados três tipos de impressos, distribuídos ao público. Estes impressos, que também integram a publicação sonora Assonâncias de silêncios [coleção], constituem proposições paralelas e ao mesmo tempo, interseccionais à experiência de adentrar a ...[sala de escuta]. 

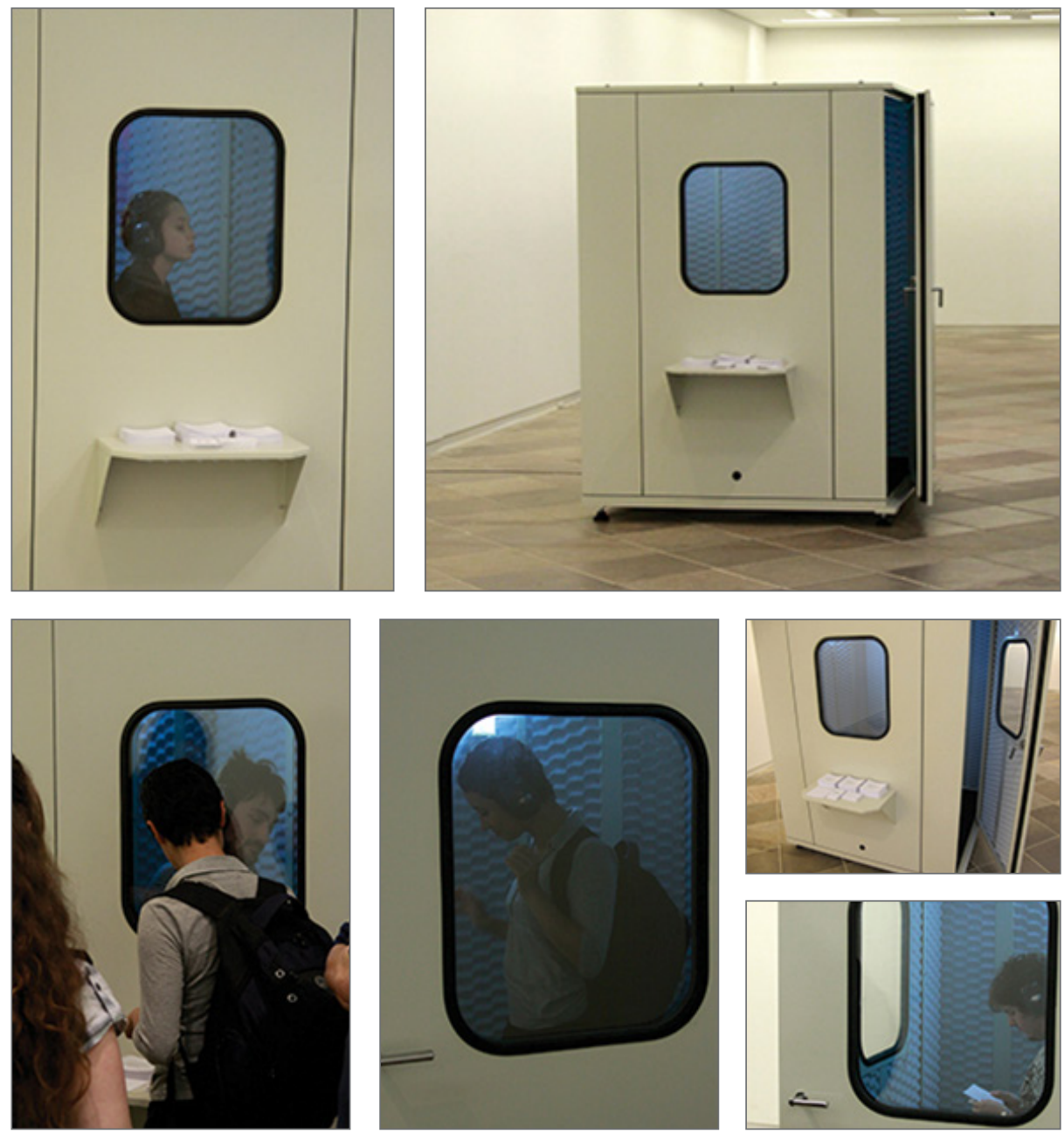

Fig. 1 - Assonâncias de silêncios [sala de escuta], 2008-2010. Fotografias de Helder Martinovsky. Acervo: Museu de Arte de Santa Catarina-MASC

Algumas situações catalisadas em Assonâncias de silêncios [sala de escuta] envolvem desde possíveis interrupções e falhas de comunicação (um silêncio interlinguagem), propondo uma espécie de ruído entre quem está dentro e quem está fora, como também indica-se a possibilidade de existir um espaço e/ou de acontecer um espaçamento, como uma pausa que pode ser adentrada numa exposição. Se como propõe Marcel Duchamp ${ }^{5}$, "o criador de som consiste num criador de espaço, um espaço originado pelo som, um espaço sonoro que possuirá uma dimensão física" (Ariza 2008, 36) (trad. nossa), 
em Assonâncias de silêncios [sala de escuta], a entrada e a saída da cabine podem ativar um espaço sonoro e insonoro, enquanto "cruzamento de móveis" (Certeau [1980] 1994), espaço que por sua vez, solicitará uma escuta que o componha ou uma escuta que delineie e module suas próprias ilhas de silêncio.

$\mathrm{Na}$ relação entre um processo de imersão e emersão, entre sair e/ou entrar dessa/nessa pausa movediça, tenho percebido que ela pode tanto atrair, como desequilibrar ou ainda, permanecer impenetrável ${ }^{6}$. Mas, pressupondose a indefinição (de contorno) de uma experiência, qual o tempo que um silêncio leva para acontecer (dentro/fora), para decantar e para ser registrado (no corpo, na escuta ou na página)? Como ouvir, escutar e compor/decompor silêncios? Ou ainda, como interromper as escutas amortecidas e automáticas, que como aponta a fonoaudióloga Beatriz Novaes (2005), cancelam tudo que se repete, transformando-o em fundo insignificante e inaudível? E essa anulação não seria uma forma de silenciamento? Porém, como pensar um silêncio enquanto fundo audível, um silêncio sonoro, e também a existência de um silêncio enquanto pausa no headspace ${ }^{7}$ ? (Schafer [1977] 2001, 171)

Atravessando as perguntas acima, John Cage escreve que "não existe silêncio" $(2007,191)$ (trad. nossa), pois há sempre algo para ser ouvido, algo que produz som/ruído, ao mesmo tempo em que o silêncio é uma questão mental, consistindo num "meio de ouvirmos o que nos cerca" (1978) ${ }^{8}$. A referência de Cage me instigou a pensar numa espécie de silêncio acústico, sondando as localizações do silêncio - onde e/ou aonde ele pode ocorrer. Talvez seja no encontro ou desencontro entre audição, escutas (Barthes), contexto e sentido (Nancy) que silêncios sonoros e acústicos podem acontecer, numa retroalimentação. Deste modo, um silêncio acústico transitaria semanticamente na própria escuta, constituindo-se enquanto situação ou estado. E se a maquinaria de sentido é algo difícil de interromper, assim como permanecer na oscilação de uma borda de sentido, propor silêncios em/para outras escutas, em instalações sonoras/insonoras, me levou a pensar também em posições e modulações acústicas.

O conceito de assonância ${ }^{9}$, presente no título do trabalho, propõe assim pensar num silêncio que ressoa no outro, no contexto sonoro que ressoa na escuta e vice-versa, desencadeando um processo de reenvio, que solicita uma escuta porosa, uma escuta-travessia, permeável, uma escuta esburacada. Tentando pensar o que difere de um silêncio a outro, o que pulsa entre um silêncio e outro, entre dentro e fora, percebi que as assonâncias acontecem tanto a 
partir das situações de audição e escuta, como nos processos de escrita e escuta. Assonâncias envolvem ressonâncias, insistências e vertigens, vinculadas ao silêncio enquanto tentativa de interrupção de sentido, o silêncio enquanto ruído incessante e a um silêncio acústico.
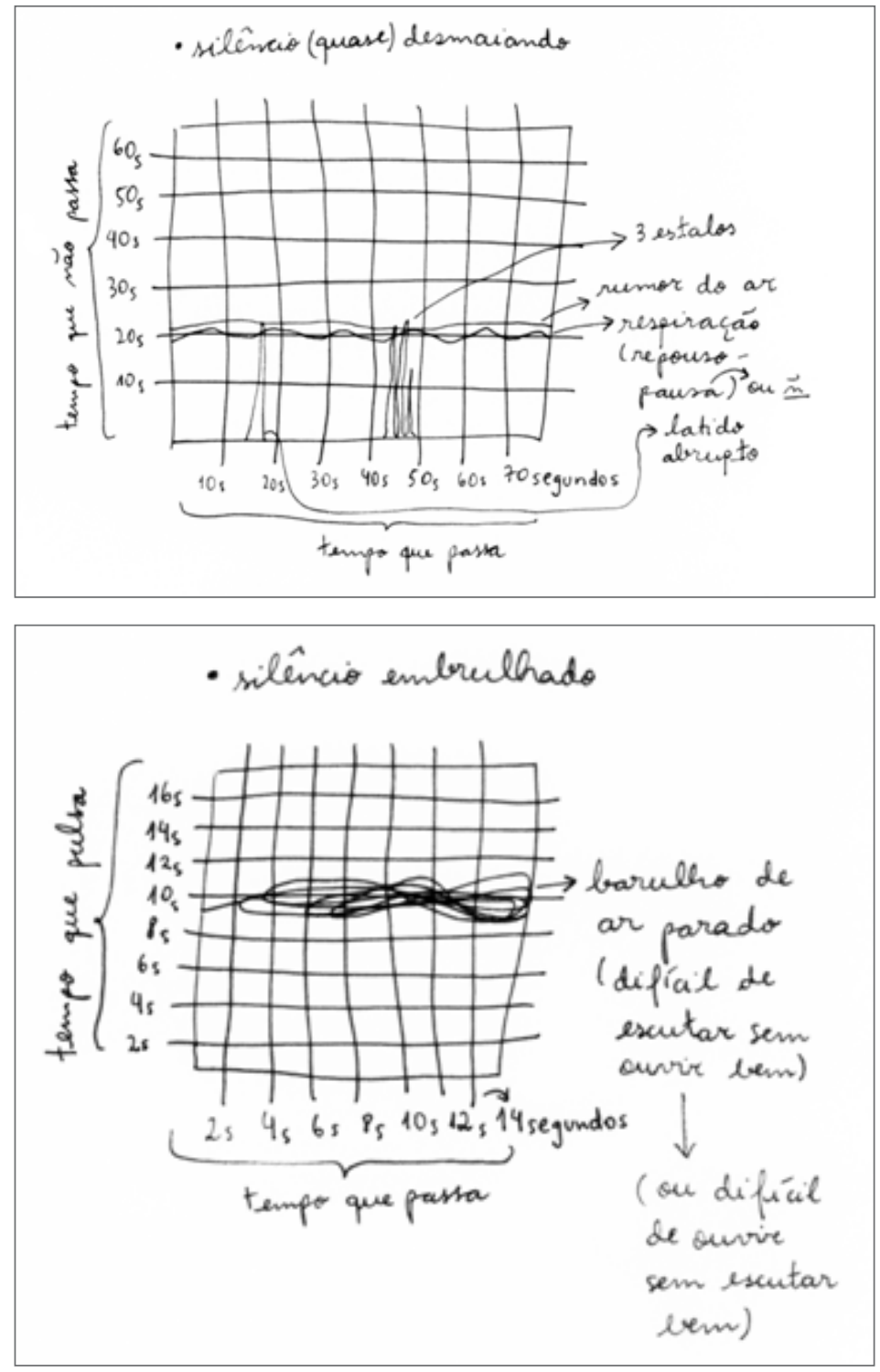

Fig. 2 - Assonâncias de silêncios [sala de escuta], 2008-2010. Detalhes de impresso. 


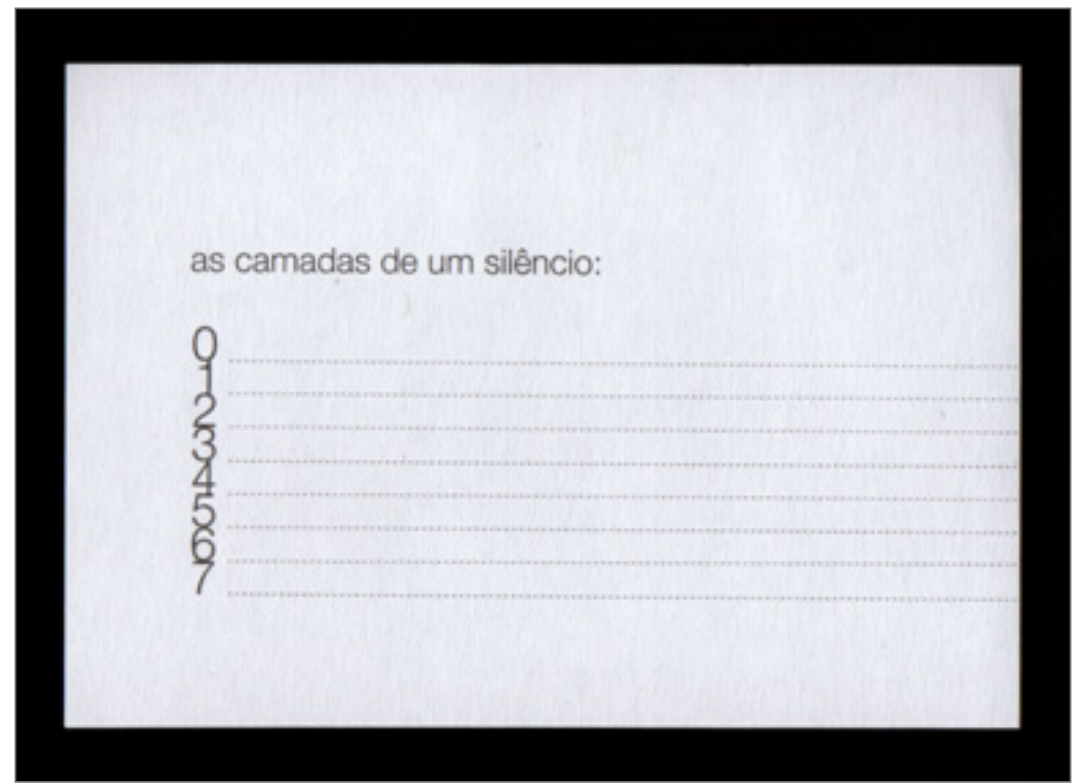

Fig. 3 - Assonâncias de silêncios [sala de escuta], 2008-2010. Detalhe de impresso.

Os impressos distribuídos na parte externa da ...[sala de escuta] lançam para o leitor-ouvinte a possibilidade de registro de sua topologia acústica, como apresentam algumas notas-desenhos de escuta que foram construídas durante o processo de seleção e edição de silêncios gravados para a publicação sonora Assonâncias de silêncios [coleção]. E se no início, consistiram em registros de experiências acústicas, enquanto anotações de processo, percebi que elas podem ser pensadas como proposições que coexistem e expandem os áudios, como possibilidades de imaginar situações silenciosas, propondo também um lançamento da escuta para silêncios ainda inauditos, esboçados e diagramaticamente concatenados. Ou como projetos e proposições-partituras de (outras) espécies de silêncios: silêncio despreparado; a sós, extra, opaco, torto; (quase) desmaiando; pendurado; avulso; embrulhado; etc.

O trabalho 60 silêncios empilhados (Fig. 4), dialoga diretamente com esses impressos e dá continuidade ao processo de colecionar silêncios. É composto por uma proposição sonora (sessenta silêncios sonoros sobrepostos), disponível para escuta num fone de ouvido suspenso (com uma pequena caixa branca sobre ele), por um banco com altura regulável, acompanhados por um pôster contendo uma nota-desenho, construída a partir dos processos de gravação, edição, audição e escuta do áudio ${ }^{10}$. 


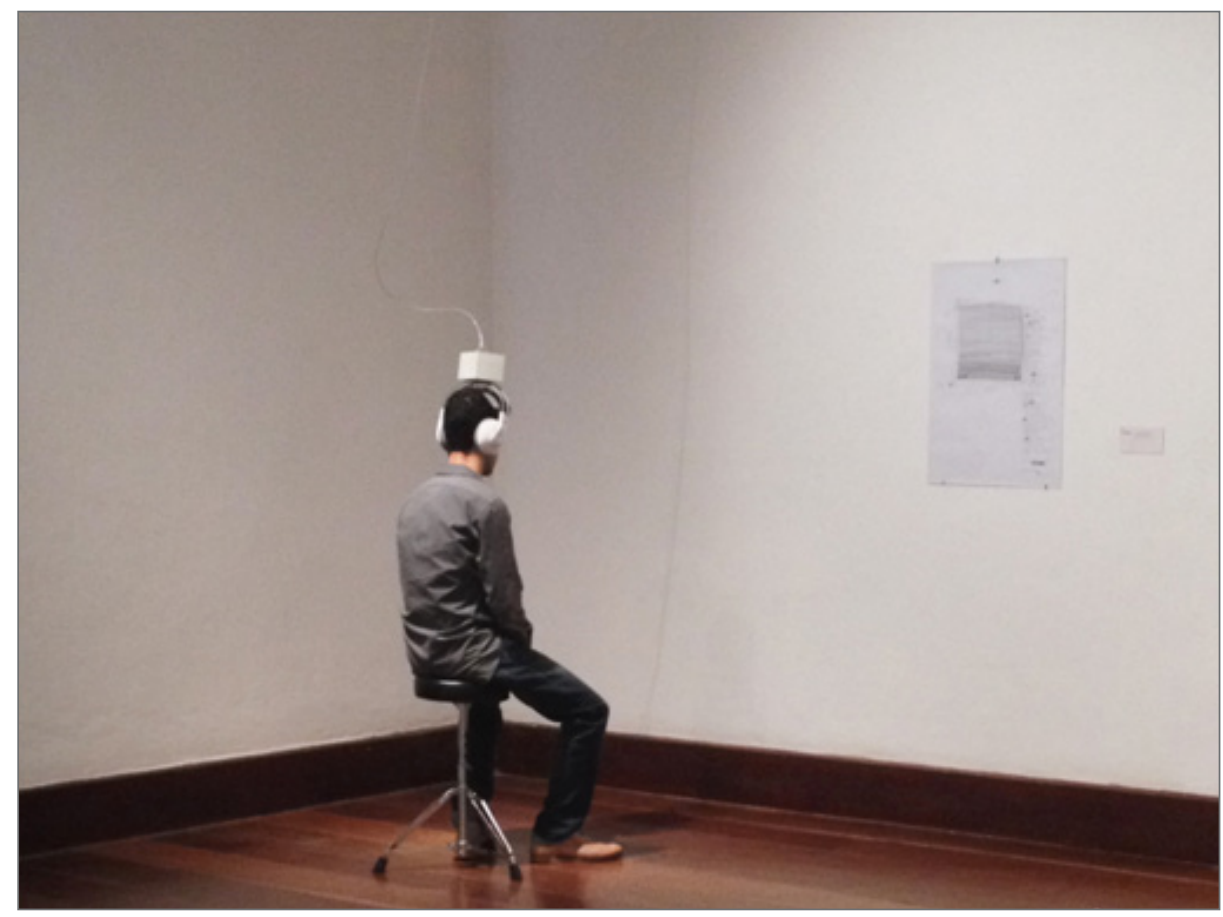

Fig. 4 - 60 silêncios empilhados, 2010-2014. Vista geral. Fotografia de Raquel Stolf. Disponível para escuta em: https://soundcloud.com/raquelstolf/60silenciosempilhados
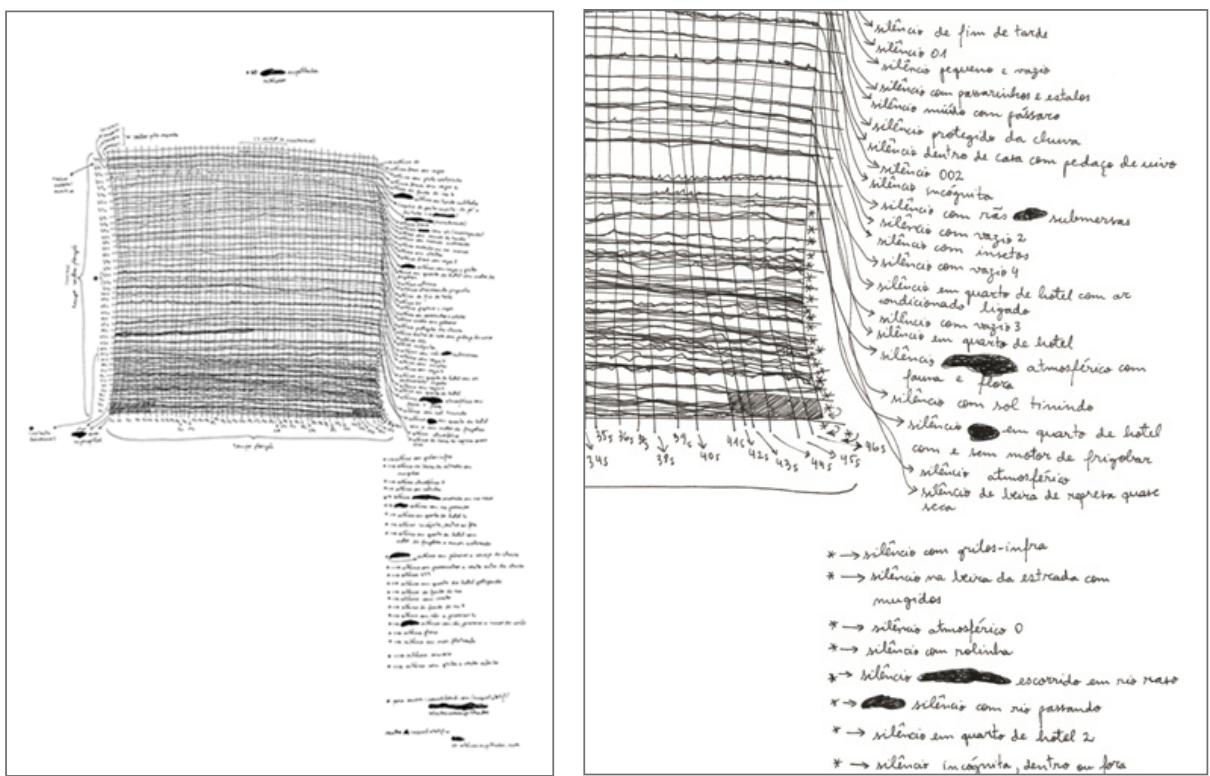

Fig. 5 - 60 silêncios empilhados, 2010-2014. Vista e detalhe de pôster.

Disponível para visualização-leitura em: http://www.raquelstolf.com/?p=3565 
Tanto em 60 silêncios empilhados, como nos impressos distribuídos na instalação Assonâncias de silêncios [sala de escuta], a proposta de (re)imaginar silêncios dialoga com a noção ou "efeito sonoro" de "phonomnesis (phonomnèse)", abordada por Jean-François Augoyard e Henry Torgue (2006). Os autores propõem pensar o som como um "efeito" que situa-se entre uma causa e um evento, envolvendo a interação entre os sons físicos ambientais e a "paisagem sonora interna" de cada indivíduo, acontecendo na relação entre um sujeito e o objeto emissor. O "efeito sonoro" denominado "phonomnesis (phonomnèse)" refere-se à atividade psíquica que envolve uma escuta interna, onde um som pode ser imaginado, mas não realmente ouvido. Os autores enfatizam que um processo de memória e uma escuta silenciosa podem ser desencadeados por uma situação vivida não necessariamente sonora - a "phonomnèse" consiste num "ato mental".

Ao propor o cruzamento entre ver-ler a nota-desenho com as camadas de silêncios indicadas (em microdescrições ou subtítulos) e escutar o empilhamento através do fone de ouvido, as conexões existentes entre a parte sonora e o aspecto visual-textual da instalação poderão ser tramadas num nível psíquico, existindo apenas em nossas mentes (como aponta Rocha Iturbide, sobre a instalação sonora). O fone de ouvido possibilita também uma experiência de concentração e dispersão num espaço acústico subjetivo (Schafer [1977] 2001), pois os fones constituem espécies de "geradores de 'vazio' ao oferecer um isolamento 'anecoico' que torna possível a escuta íntima graças a um duplo bloqueio -sempre variável mediante o controle de volume-; o de não escutar e o de preservar o que escutamos em relação à realidade acústica circundante [...]." (López Rodríguez 2010) (trad. nossa). A escuta de silêncios através de fones de ouvido insinua um mergulho num duplo vazio, tendo como uma espécie de testemunha a nota-desenho, enquanto registro/ escuta do processo e como proposição-partitura para imaginar as camadas antes da pilha.

Essa relação sinuosa entre imaginar/escutar e ver/ouvir/escutar apresenta-se também no trabalho de Robert Morris intitulado Box with the Sound of its Own Making (1961), que consiste numa caixa de madeira, em cujo interior há um alto-falante que amplifica uma gravação com duração de três horas e meia, com os ruídos produzidos durante o processo de construção do próprio objeto. Brandon LaBelle (2006) sublinha que o trabalho de Morris ressoa enquanto objeto auto-referencial, na medida em que ouvimos os ruídos do processo ao mesmo tempo em que vemos o resultado dessa operação. Enfatiza que Box... articula um deslocamento entre uma presença imediata e uma gravação/reprodução como mediação dessa presença. Enquanto objeto, ela está 
ao mesmo tempo aqui e lá, no passado e no presente, sendo audível e fixa. $E$, sua presença parece dependente da gravação do processo de sua feitura. Outra questão importante apontada por LaBelle é que o trabalho de Morris envolve uma percepção que é textual, no sentido de que seu componente sonoro articula-se enquanto algo a ser lido. Box... solicita uma "escuta ativa que é analítica: o que eu ouço não completa minha experiência, enquanto plenitude perceptual alcançada..." (Labelle 2006, 84) (trad. nossa). O trabalho de Morris constitui uma referência para os projetos aqui abordados, ao passo em que articula uma situação que solicita uma escuta pensativa ou interrogativa. Envolve tanto uma expectativa sonora e, paradoxalmente, incita uma retrospecção através da audição dos registros de um processo, os quais poderiam ser pensados como uma partitura pós-execução.

Por fim, tanto Assonâncias de silêncios [sala de escuta] como 60 silêncios empilhados sinalizam a escuta como campo de experimentações ou como uma espécie de laboratório, no sentido em que propõe Peter Galison, numa entrevista com Barbara Vanderlinden (2001), como uma situação de dispersão na qual não se pode mais definir onde o experimento está acontecendo. Galison sublinha que não há uma definição padrão ou única de laboratório, e Vanderlinden pontua a definição de "auto-laboratório" de Francisco Varela, que propõe uma espécie de "laboratório de si" (onde, por exemplo, a meditação pode ser concebida como um laboratório). Hans Ulrich Obrist, curador do projeto Laboratorium realizado com Vanderlinden, pergunta: "Como começa uma experiência? Uma experiência tem fim? Onde ela se torna pública, onde seu resultado ganha aceitação pública? Pode um experimento falhar?" (Obrist \& Vanderlinden 2001, 17).

O quanto perdura uma experiência? $E$, se nossa sensação do tempo não ocorre de maneira contínua e fixa, mas consiste em "acontecimentos mais ou menos complexos chamados durações de presença” (Wisnik 1989, 205), constituindo uma espécie de "pulso mental", um silêncio acústico pode não se propagar ou não durar?

Referências

Ariza Pomareta, Javier. 2008. Las imágenes del sonido: Una lectura plurisensorial en el arte del siglo XX. Cuenca: Universidad de Castilla-La Mancha

Augoyard, Jean-François \& Henry Torgue, eds. 2006. Sonic Experience: A Guide to Everyday Sounds. Montreal, QB: McGill-Queen's University 
Barthes, Roland. (1982) 1990. O Óbvio e o Obtuso. Ensaios Críticos III. São Paulo: Nova Fronteira

Cabanne, Pierre. 1987. Marcel Duchamp: Engenheiro do Tempo Perdido. São Paulo: Perspectiva

Cage, John. 1978. “John Cage: Dois toques para o Brasil”. Entrevista. Código 3 (Salvador, Bahia)

- 1985. De segunda a um ano. Tradução de Rogério Duprat e Augusto de Campos. São Paulo: Hucitec

— 2007. Silencio. Trad., Pilar Pedraza. Madrid: Árdora

Certeau, Michel de. (1980) 1994. Invenção do Cotidiano I: Artes de fazer. Petrópolis: Vozes

Costa, José Manuel. 2010. “Arte Sonoro”. Número especial, Exit Express 54 (oct.)

Duchamp, Marcel. 2007. Duchamp du signe: Ecrits réunis et présentés por Michel Sanouillet. Paris: Flammarion

Labelle, Brandon. 2006. Background noise: Perspectives on Sound art. London: Continuum Books

Lagnado, Lisette. 2002. "Ateliê, laboratório e canteiro de obras". Jornal Folha de São Paulo, Caderno Mais! 13/01/2002

López Rodríguez, Juan-Gil [Xoán Xil, seud.]. 2010. "La escucha íntima: In-head sound immersion”. Mediateletipos.net, 12 March. www.mediateletipos.net/archives/12058\#more12058

Nancy, Jean-Luc. 2007. A la escucha. Traducción, Horacio Pons. Buenos Aires: Amorrortu

Neuhaus, Max. 2012. "Sound Works". Max-neuhaus.info, modificada pela última vez 22 feb., www.max-neuhaus.info/soundworks

Novaes, Beatriz. 2005. "A vez do outro". En Sobre o silêncio (entrevistas com vários autores) por Andréa Bomfim, 161-72. Perdigão. São José dos Campos: Pulso

Obrist, Hans-Ulrich \& Barbara Vanderlinden, eds. 2001. Laboratorium. Exhibition, Antwerp, 27 June-3 October 1999. Köln: DuMont

Pritchett, James. 2009. “Lo que el silencio enseño a John Cage: la historia de 4'33”. En La anarquía del silencio: John Cage y el Arte experimental [exposición], director del proyecto, Bartomeu Marí; comisaria, Julia Robinson, 166-77. Barcelona: MACBA

Rocha Iturbide, Manuel. 2003. "La instalación sonora”. Ólobo 4. www.uclm.es/artesonoro/ Olobo4/html/rocha.html

Roden, Steve. 2005. "Active listening”. Soundwalk 05 catalog. http://www.soundthreshold.org/ download/roden active.pdf

Santos, Fátima Carneiro dos. 2009. "Escutando as paisagens sonoras urbanas-Uma escuta nómade”. Rizoma.net, seção Esquizofonia, 58-65. http://www.intervencaourbana.org/ rizoma/rizoma esquizofonia.pdf

Schafer, R. Murray. (1977) 2001. A afinação do mundo: Uma exploração pioneira pela história passada e pelo atual estado do mais negligenciado aspecto de nosso ambiente: a paisagem sonora. São Paulo: Unesp

Stolf, Maria Raquel da Silva. 2011. "Entre a palavra pênsil e a escuta porosa: [Investigações sob proposições sonoras]". Tese Univ. Federal do Rio Grande do Sul

Wisnik, José Miguel. 1989. O som e o sentido. São Paulo: Companhia das Letras 
${ }^{1}$ Esse projeto compõe um dos blocos de minha tese de doutorado, intitulada Entre a palavra pênsil e a escuta porosa [investigações sob proposições sonoras], orientada pelo Prof. Dr. Hélio Fervenza no PPGAV-UFRGS, sendo que este texto desdobra algumas de suas reflexões, indicando a continuidade de minhas investigações.

${ }^{2}$ Atividades de pesquisa como professora do Departamento de Artes Visuais e do Programa de Pós Graduação em Artes Visuais, PPGAV/UDESC: Investigações sob publicações sonoras [entre disco, palavra-partitura e notas-desenhos de escuta] (2011-2014) e Processos de escrita / Escuta de processos [articulações entre voz, palavra e silêncio em publicações sonoras] (2015-2017).

${ }^{3}$ Disponível em: http://www.max-neuhaus.info/soundworks. Acesso em 30/01/2011.

4 A publicação sonora Assonâncias de silêncios [coleção] (2007-2010) integra esse processo. Consiste numa coletânea de silêncios gravados em diferentes contextos, agrupados num CD de áudio com material impresso, tendo 500 exemplares. O CD divide-se em blocos denominados: silêncios preparados; silêncios acompanhados; silêncios com falhas; silêncios empilhados; fundo do mar sob ruído de fundo. Para ver-escutar: http://www.raquelstolf.com/?p=467. Outros trabalhos do projeto: http://www.raquelstolf.com/?cat=26. Acesso em 11/11/2015.

${ }^{5}$ A nota Sculpture Musicale, de Duchamp (2007, 47), do trabalho La Mariée mise à nu par sés célibataires, même (La Boîte verte) (1934), propõe "Sons durando e partindo de diferentes pontos e formando uma escultura sonora que dura..." (trad. nossa).

${ }^{6}$ Como aponta Pritchett $(2009,177)$ sobre a peça 4'33" de Cage, "a experiência do silêncio não é algo que possa ser comunicado entre uma pessoa e outra”(trad. nossa). Ao mesmo tempo, o silêncio do qual falava Cage, é algo acessível para todas e para cada uma das pessoas. Fátima C. dos Santos (2008) escreve que Cage fez "soar o silêncio em 4'33"'” através de um "enquadramento temporal" vinculado à proposta de uma escuta participativa e inventiva por parte do ouvinte, "onde o ato de escutar constitui-se também em um ato de compor".

7 Para Schafer ([1977] 2001, 171-2), o "Head space é uma expressão popular entre os jovens e refere-se à área da mente que não pode ser alcançada por nenhum telescópio. [...] No espaço da cabeça, na audição com fones de ouvidos, os sons não apenas circulam em volta do ouvinte, mas literalmente, parecem emanar de pontos situados dentro do próprio crânio..."

8 "O silêncio, na realidade, não existe. Nunca existe uma ausência de som, que é como os dicionários definem o silêncio. O silêncio é simplesmente... uma questão mental. Uma questão de saber se uma pessoa está escutando os sons que não está provocando. Não sou eu que faço os pássaros cantarem, mas eu os ouço e não estou falando: a isso chamamos de silêncio. O silêncio é um meio de ouvirmos o que nos cerca" (Cage 1978). Em sua experiência na câmara anecoica, narrada no livro De segunda a um ano (1985), Cage sublinha as mesmas reflexões acima, indicando a escuta do ruído incessante de seu corpo (o som grave do sangue em circulação e o agudo do sistema nervoso).

${ }^{9}$ A denominação Assonâncias de silêncios foi construída a partir de uma fala de Duchamp, em Marcel Duchamp: Engenheiro do Tempo Perdido. Duchamp responde à uma pergunta de Pierre Cabanne - "Você realmente ama as palavras?" - insinuando as assonâncias e os trocadilhos verbais como possibilidades para propor "palavras deformadas pelo seu sentido" (1997, 153). A assonância envolve a semelhança de sons em palavras quando estão 
próximas, sendo entendida também como a repetição de vogais das palavras num poema. Porém, não a repetição de um mesmo ou de uma matriz, mas de micro-variações.

${ }^{10}$ A proposição sonora integra o segundo volume da publicação Assonâncias de silêncios [coleção] (em processo) e o pôster integrou também a publicação Recibo, edição pôster, 2014\2015, edições Traplev Orçamentos.

(Artículo recibido 30-11-15 ; aceptado 09-12-15) 